\title{
Comments on: Is Pethidine Safe during Labor? Systematic Review
}

\author{
Tatiana Henriques Leite ${ }^{1}$ Emanuele Souza Marques ${ }^{1}$ Vitor Barreto Paravidino ${ }^{1}$ \\ ${ }^{1}$ Social Medicine Institute, Universidade do Estado do Rio de Janeiro, \\ Maracanã, RJ, Brazil \\ Rev Bras Ginecol Obstet 2018;40:656-657. \\ Address for correspondence Tatiana Henriques Leite, PhD, Social \\ Medicine Institute, Universidade do Estado do Rio de Janeiro, R. São \\ Francisco Xavier, 524, sala 1006 a, 20550-900, Maracanã, RJ, Brazil \\ (e-mail: henriques.tatiana@gmail.com).
}

Dear Editor,

Several studies demonstrate that pethidine is safe and effective for the parturient; ${ }^{1}$ however, its use has been widely questioned because of the possible side effects on the fetus. Nunes et al $(2017)^{2}$ conducted a systematic review to determine if pethidine during labor is safe for the conceptus; however, some important limitations of this review should be discussed.

The main issue is related to the search strategy. According to the Cochrane Handbook for Systematic Reviews, ${ }^{3}$ three databases should be considered for a clinical trial search: Medline, Embase and CENTRAL. In addition, in Brazil, the Ministry of Health recommends that a systematic review should include, at least, four essential databases (Medline, Embase, CENTRAL and Lilacs) and an area-specific one. ${ }^{4}$ Nevertheless, Nunes et $\mathrm{al}^{2}$ described that only two databases (Medline and Virtual Health Library Biblioteca Virtual em Saúde [BVS, in the Portuguese acronym]) were used.

The authors reported the search was performed using the keywords pethidine in labor, alone or combined with each other; however, this search strategy is incorrect. Searches should be conducted using Medical Subject Headings (MeSh terms) and Boolean operators. According to the literature, there are several pethidine synonymous (meperidine, piperosal, dolosal, demerol and dolantine), and these terms were not considered.

Combining these two limitations mentioned above and the same inclusion/exclusion criteria used by the authors, at least eight eligible articles were not included in this review. ${ }^{5-12}$ This number represents an underestimation of, at least, $50 \%$ of all papers included in this systematic review. In addition, the search strategy was limited to a 16 -year period. This approach ignores all evidence produced before the considered period and, according to the Cochrane Handbook, this is not indicated. ${ }^{3}$

Another important issue regards the lack of a specific question structured by the population, intervention, control, outcome (PICO) process. It is not clear to the readers who the participants $[\mathrm{P}]$ were (nulliparous, multiparous, high risk pregnancy); the intervention [I] (drug concentration, drug administered intravenously or intramuscularly, combined or not with other medications, at which labor stage the intervention was applied); the control group [C] (placebo, other drugs) and how the outcome was assessed [0]. All these characteristics could influence the result of the review. Therefore, this information should be collected and presented in a subgroup analysis.

Other important limitations should be highlighted: (1) the authors did not perform a risk of bias assessment. This is the only available strategy to evaluate internal validity-an important criterion in epidemiologic studies; (2) the authors did not describe the systematic review following the preferred reporting items for systematic reviews and meta-analyses (PRISMA) criteria. ${ }^{13}$ Study selection, data collection process, flowchart and other aforementioned parameters were not present as recommended; (3) the authors reported that "sample size bellow 25 patients" is an exclusion criterion because they are more prone to erroneous conclusions. However, this statement is incorrect. Actually, a sample size is specific for a given study and 25 patients or less can be adequate, considering the parameters used.

In conclusion, although the authors of this review analyzed an important question, the limitations and methodological errors mentioned above might have influenced the results. Therefore, any conclusion or recommendation concerning the results of this review should be interpreted with caution. Future systematic reviews and meta-analyses should perform an exhaustive search of the literature and use an appropriate methodological approach.

\section{Authors' Reply}

Dear Editor,

The authors have nothing to declare about the letter to editor.
DOI https://doi.org/ 10.1055/s-0038-1675201. ISSN 0100-7203.
Copyright $\odot 2018$ by Thieme Revinter Publicações Ltda, Rio de Janeiro, Brazil
License terms

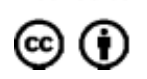




\section{Conflicts to Interest}

The authors have no conflicts of interest to declare.

\section{References}

1 Smith LA, Burns E, Cuthbert A. Parenteral opioids for maternal pain management in labour. Cochrane Database Syst Rev 2018;6: CD007396 Doi: 10.1002/14651858.CD007396.pub3

2 Nunes RR, Colares PGB, Montenegro JP. Is pethidine safe during labor? Systematic review. Rev Bras Ginecol Obstet 2017;39(12): 686-691 Doi: 10.1055/s-0037-1604065

3 Higgins JPT, Green S. Cochrane Handbook for Systematic Reviews of Interventions Version 5.1.0. London: The Cochrane Collaboration; 2011

4 Ministério da Saúde. Secretaria de Ciência, Tecnologia e Insumos Estratégicos. Diretrizes Metodológicas: Elaboração de Revisão Sistemática e Metanálise de Ensaios Clínicos Randomizados. Brasília, DF: Ministério da Saúde; 2012

5 Abdollahi M-H, Mojibian M, Pishgahi A, et al. Intravenous paracetamol versus intramuscular pethidine in relief of labour pain in primigravid women. Niger Med J 2014;55(01):54-57 Doi: 10.4103/ 0300-1652.128167

6 Direkvand-Moghadam A, Delpisheh A, Direkvand-Moghadam A, Fathollahi $\mathrm{E}$. The effects of pethidine on the duration of active labor in nulliparous women. J Bas Res Med Sci. 2015;1:60-64

7 Blair JM, Dobson GT, Hill DA, McCracken GR, Fee JPH. Patient controlled analgesia for labour: a comparison of remifentanil with pethidine. Anaesthesia 2005;60(01):22-27 Doi: 10.1111/j.13652044.2004.03975.x

8 Kamyabi Z, Naderi T, Ramazani A. A randomized, placebo-controlled trial of the effects of pethidine on labor pain, uterine contractions and infant Apgar score. Ann Saudi Med 2003;23(05): 318-320 Doi: 10.5144/0256-4947.2003.318

9 Mobaraki N, Yousefian M, Seifi S, Sakaki M. A randomized controlled trial comparing use of enthonox with pethidine for pain relief in primigravid women during the active phase of labor. Anesth Pain Med 2016;6(04):e37420

10 Rezk M, El-Shamy ES, Massod A, Dawood R, Habeeb R. The safety and acceptability of intravenous fentanyl versus intramuscular pethidine for pain relief during labour. Clin Exp Obstet Gynecol 2015;42(06):781-784

11 Soontrapa S, Somboonporn W, Komwilaisak R, Sookpanya S. Effectiveness of intravenous meperidine for pain relief in the first stage of labour. J Med Assoc Thai 2002;85(11):1169-1175

12 Thurlow JA, Laxton CH, Dick A, Waterhouse P, Sherman L, Goodman NW. Remifentanil by patient-controlled analgesia compared with intramuscular meperidine for pain relief in labour. Br J Anaesth 2002;88(03):374-378 Doi: 10.1093/bja/ 88.3.374

13 Liberati A, Altman DG, Tetzlaff J, et al. The PRISMA statement for reporting systematic reviews and meta-analyses of studies that evaluate health care interventions: explanation and elaboration. PLoS Med 2009;6(07):e1000100 Doi: 10.1371/ journal.pmed.1000100 